\title{
Moving forward with CMAJ.ca
}

$\mathrm{E}$ ven before Tim Berners-Lee proposed, in 1989 , the global hypertext project now known as the World Wide Web, the electronic exchange of scientific information had already begun to flourish. (Some of us might recall using "gopher.") When, in I993, Berners-Lee and his then-employer CERN made their hypertext link software available free to all users, the rate of information exchange exploded; bits and bytes compounded into googols; the Internet era had begun.

Many people, including the current editor of this Journal, were slow to recognize the far-reaching implications of Web technology and the potential for "open and free" access to transform the habits and expectations of scientific publishing. The distribution of new findings can now be instantaneous and world-wide, the scope for collaboration and crossfertilization limitless. Measures of influence are also changing: it is not only what and where you publish that counts in a scientific career, but the rapid dissemination and uptake of results by an increasingly globalized community of researchers.

Peer-reviewed journals have existed since the r66os (the first English-language journal being the Philosophical Transactions of the Royal Society). For almost three and a half centuries the mode of scholarly publication remained essentially unchanged: journals appeared at intervals, were circulated to a limited number of subscribers and libraries, and were read by those with adequate means. However, by the turn of the 2Ist century, $75 \%$ of academic journals were available online as well as in print, and more than rooo online-only peer reviewed journals had appeared. ${ }^{1}$ MEDLINE, the main source for locating health sciences publications, became open and free in I997. CMAJ presented an online version in mid-I995, although it contained only some of the content of the print journal. Two years, in 1999 , eCMAJ, a full-text, searchable and hyperlinked "copy" of the print journal was placed online and made available free to all users. We've now renamed this electronic version CMAJ.ca, although not without some nostalgia for the cute "e" of the enthusiastic late Iggos.

Almost immediately, our print and electronic versions began to diverge in content, readership and (given the capacity for rapid posting) frequency of publication. The print copy is mailed to about 65000 individuals and institutions; $90 \%$ of individual subscribers are members of the CMA. CMAJ.ca is accessed by about 250000 "distinct hosts" computer terminals with one or multiple users - who generate I.5 to 2 million "page views" ("hits") a month. Of our online readers, about one-third are Canadian; the others reach us from $\mathrm{II}_{3}$ different countries. Only $3 \mathrm{I} \%$ of our online readers are physicians.

Changes to the print version of $C M A J$ were described in last issue's editorial. ${ }^{2}$ Although, Io years ago, the electronic version held only part of the print content, now the electronic edition accommodates more material than the print edition. This is especially true for research articles, which in their electronic version include a detailed methods section, extra tables and figures, appendices and various online-only data supplements such as survey questionnaires, video clips, animated graphics and audio material.

Over the next year we expect changes in both our print and electronic formats to continue: the print version will be tailored for easier reading and browsing, the electronic version for easier searching, retrieval and hyperlinking to other sources. We will modestly expand our editorial staff to meet these challenges (see page I2IO).

The electronic version of $C M A J$ will also improve our editorial service to authors. Our move to an online manuscript tracking system has evidently encouraged more submissions and has also diminished the time from submission to first manuscript decision (including peer review) to just $3 \mathrm{I}$ days. Over the next I2 months, in addition to fast-tracking all randomized-controlled trials, we will publish online in advance of print publication as many articles as our staff and budgets can manage, thus shortening the interval between article acceptance, publication and listing on PubMed.

These changes have important business implications. Although the costs of an electronic version are marginal as an add-on to print publication, the average editorial costs of processing, soliciting and editing submissions are not. At the moment these are paid for almost exclusively out of printjournal advertising (both pharmaceutical and classified). Although we don't expect print readership to diminish in the near term, we must find other economic models for openaccess electronic publication, such as subscriptions, author and institutional charges, philanthropy, government grants and blends of these.

As daunting as it is to evolve in lock-step with the new technologies of scientific communication, the alternative is obsolescence. - CMAJ

\section{REFERENCES}

I. Willinsky J. The unacknowledged convergence of open source, open access and open science. In: First Monday 2005;Io(8). Available: http://firstmonday.org/issues /issuero_8/willinsky/index.html

2. A renewed and improved $C M A J$ [editorial]. $C M A J$ 2005;173(9):1009. 